\title{
Temperature and the Viscosity of Protoplasm.
}

\author{
By \\ C. F. A. Pantin, B.A., \\ Assistant Physiologist at the Plymouth Laboratory. \\ With 1 Figure.
}

DURING the investigation of amœboid activity (17) it became necessary to know the effect of temperature on the viscosity of protoplasm. In the marine amœbæ studied the viscosity appeared to rise as the temperature fell, especially near $0^{\circ} \mathrm{C}$. Greely (9) has noted similar changes in the protoplasm of fresh-water amœbæ and other protozoa. An increase in viscosity with a fall of temperature also accounts for the parallel effects of cold and loss of water on the protoplasm of various animals (Greely, $\mathbf{7}$ and 8).

The amœbæ were not suitable for the quantitative determination of relative changes in viscosity. Weber (20 and 21$)$ investigated these changes quantitatively in certain plant cells. He found that the viscosity rose as the temperature fell in the same way that it does in protein solutions, but more rapidly. Perhaps this might be expected since Chick (3) has shown that for protein solutions the rise in viscosity as the temperature falls becomes greater as the concentration of protein increases, and the protein concentration in protoplasm is probably high.

However, Heilbrunn (11) has shown that the viscosity of sea-urchin eggs falls as $0^{\circ} \mathrm{C}$. is approached. In his most recent paper (13) he has determined quantitatively the effect of temperature on the viscosity of Cumingia eggs. He finds the viscosity to be maximum near $15^{\circ} \mathrm{C}$., and to fall rapidly as the temperature is raised or lowered from this point. Near $0^{\circ} \mathrm{C}$. the viscosity rises again very sharply.

Heilbronn (10) has obtained somewhat similar results with certain Myxomycetes, though the variations of the viscosity are less marked. He suggests that the viscosity of protoplasm, as opposed to a purely physical system, can undergo " auto-regulation " by the protoplasm itself.

Temperature thus has widely different effects in different cases, and until more have been studied it is difficult to draw conclusions as to the general effect of temperature on the viscosity of protoplasm. But since the viscosity of the constituents of protoplasm must rise as the tem- 
perature falls, we would expect the rise in viscosity first mentioned, noted by Weber (21 and 22) and others, to be the normal effect of a fall in temperature on protoplasm, unless secondary changes occur. Weber points out that in other cases the peculiar variations of viscosity are probably brought about by such secondary changes (e.g. changes in permeability).

Again, variations in the viscosity must arise from changes in the state of the protoplasm itself, and such changes must have an influence on processes taking place in the protoplasm. But although Heilbrunn (13) points out that the viscosity temperature curve for Cumingia eggs is roughly similar to the curve showing the relation of crossing-over in Drosophila to temperature, yet the curves showing the relation of the majority of biological processes to temperature show no relation to such a viscosity temperature curve. For instance, the curve relating temperature to the rate of beat of the Terrapin heart (19) is a smooth curve gradually reaching zero near $0^{\circ} \mathrm{C}$.: if the state of the protoplasm changed with the temperature, as in Cumingia eggs, one would expect the change to be reflected by a deviation from the observed smooth curve, this deviation being maximal where the viscosity was maximal. On the other hand, the gradual manner in which this and similar curves reach zero near $0^{\circ} \mathrm{C}$. is in keeping with the assumption that in most of these cases the viscosity rises regularly as the temperature falls, becoming very great near $0^{\circ} \mathrm{C}$.

\section{Material, Methods, and Results.}

The viscosity of the protoplasm of the immature eggs of Nereis diversicolor (the normal, not the heteronereis form) appears to rise as the temperature falls. The following experiments were performed to determine this rise quantitatively, and thus to find the order of magnitude of the viscosity changes in cases such as this.

The method employed was that of Heilbrunn (12). Individual worms, full of eggs, were opened and the eggs washed out with natural sea-water ( $\mathrm{pH} 7 \cdot 8$ to 8.2 in all experiments). During the experiment the eggs were kept in a dish surrounded by water containing ice; if kept at room temperature the viscosity was found to alter slightly before the end of the experiment. Eggs were taken from the dish and centrifuged in a hæmatocrit attachment to the centrifuge at a given temperature for different periods. The temperature was controlled by enclosing the hæmatocrit attachment in a small inner chamber, surrounded by a large outer chamber containing water (or ice) at the desired temperature. The hæmatocrit attachment was first heated or cooled to the desired temperature, and then rapidly fixed on to the centrifuge spindle in the inner chamber and the apparatus closed. A thermometer entered the inner chamber, and as soon as the desired temperature was registered the eggs 
were centrifuged. The hæmatocrit attachment was $14.5 \mathrm{~cm}$. in diameter, and in these experiments it was turned at 108 revolutions per second.

After centrifuging for a certain time a black granular cap formed at the lower side of the egg. The time required for this cap to form was used as a measure of the viscosity of the protoplasm. Some eggs form the cap a little more readily than others, so that as the duration of centrifuging increases the proportion of eggs with fully developed caps increases. The change from the condition in which caps are absent to that in which all the eggs have caps occurs over a definite range of the duration of centrifuging.

All intermediate stages of cap development occur. An arbitrary standard was therefore applied above which the cap was considered to be developed. The standard taken was that degree to which the cap must be developed so that it be just visible when viewed normally, though readily visible when viewed in profile. In this way the number of eggs that had developed the cap could be counted for a particular duration of centrifuging. Table 1 shows the results of a typical experiment giving the ratio of capped to uncapped eggs for various periods of centrifuging at different temperatures. The experiments had to be done as rapidly as possible, so the counts were limited to 40 eggs.

TaBle 1.

Eggs of Nereis diversicolor.

$\begin{array}{cccccc}\text { Temperature. } & \begin{array}{c}\text { Centrifuging } \\ \text { time, } \\ \text { in seconds. }\end{array} & \begin{array}{c}\text { Eggs } \\ \text { not capped. }\end{array} & \begin{array}{c}\text { Eggs } \\ \text { capped. }\end{array} & \begin{array}{c}\text { Capped. } \\ \text { Not capped. }\end{array} & \begin{array}{c}\text { Time for 50\% to } \\ \text { form cap. }\end{array} \\ & 60 & 0 & 40 & \infty & \\ -1^{\circ} \text { C. } & 50 & 11 & 29 & 2 \cdot 6 & 46 \text { secs. } \\ & 40 & 28 & 12 & 0 \cdot 43 & \\ & 30 & 40 & 0 & 0 & \\ +10^{\circ} & 30 & 0 & 40 & \infty & \\ & 25 & 12 & 28 & 2 \cdot 3 & 23 \cdot 5 \text { secs. } \\ & 20 & 32 & 8 & 0 \cdot 25 & \\ +19^{\circ} & 15 & 38 & 2 & 0 \cdot 05 & \\ & 25 & 0 & 40 & \infty & \\ & 20 & 4 & 36 & 9 \cdot 0 & \\ & 15 & 33 & 7 & 0 \cdot 21 & \\ +30^{\circ} & 10 & 40 & 0 & 0 & \\ & 16 & 1 & 39 & 39 \cdot 0 & \\ & 12 & 28 & 12 & 0 \cdot 43 & 13 \cdot 2 \text { secs. } \\ & 10 & 37 & 3 & 0 \cdot 08 & \\ & 8 & 40 & 0 & 0 & \end{array}$


By interpolation an approximate value for the time required for $50 \%$ of the eggs to become capped was determined for each temperature (see last column). These times give a relative measure of the viscosity at that temperature.

The difference between the logarithm of the time required for the cap to form at any temperature and the logarithm of the time taken at $10^{\circ} \mathrm{C}$. gives the logarithm of the relative viscosity compared with that at $10^{\circ} \mathrm{C}$. By taking the mean of these logarithmic differences from several experiments for a particular temperature, the mean viscosity at that temperature relative to the viscosity at $10^{\circ} \mathrm{C}$. is found.

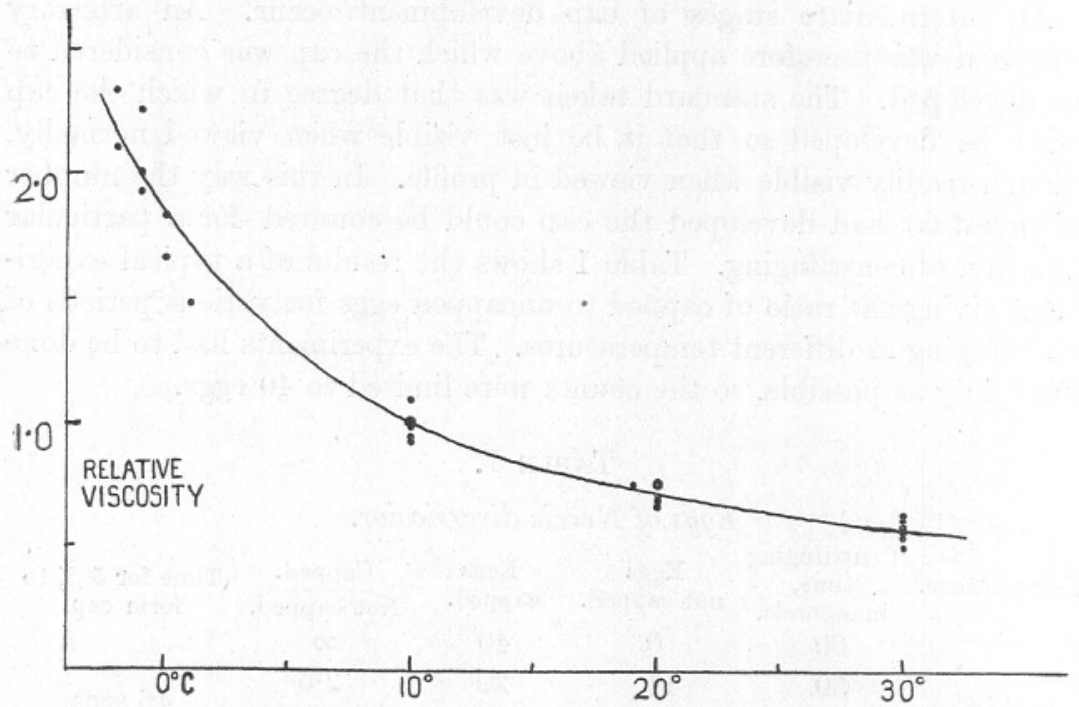

FIG. 1.-Curve showing relative viscosity of Nereis eggs at different temperatures. The curve is the mean of eight experiments, the particular values of which are plotted about the curve. Several of the values fall upon the same point.

Table 2 gives the mean relative viscosity at different temperatures from eight experiments, taking the relative viscosity at $10^{\circ} \mathrm{C}$. as unity. Fig. 1 shows the curve obtained by plotting these mean values against

TABLE 2 .

\begin{tabular}{|c|c|c|c|c|}
\hline \multicolumn{2}{|c|}{ Nereis eggs. } & \multirow{2}{*}{\multicolumn{2}{|c|}{ Nereis eggs. }} & \multirow{3}{*}{$\begin{array}{c}\begin{array}{c}\text { Protoplasm of } \\
\text { phaseolus } \\
(21) .\end{array} \\
\text { Q } 10 .\end{array}$} \\
\hline $\begin{array}{c}\text { Mean } \\
\text { temperature. }\end{array}$ & $\begin{array}{c}\text { Mean relative } \\
\text { viscosity. }\end{array}$ & & & \\
\hline \multirow{4}{*}{$\begin{array}{c}-0 \cdot 7^{\circ} \mathrm{C} . \\
+10 \cdot 0 \\
20 \cdot 0 \\
30 \cdot 0\end{array}$} & \multirow{4}{*}{$\begin{array}{l}1.95 \\
1 \cdot 00 \\
0 \cdot 71 \\
0 \cdot 57\end{array}$} & Temperature. & Q 10. & \\
\hline & & $0^{\circ}-10^{\circ}$ & $1 \cdot 84$ & 1.51 \\
\hline & & $10^{\circ}-20^{\circ}$ & $1 \cdot 40$ & $1 \cdot 41$ \\
\hline & & $20^{\circ}-30^{\circ}$ & $1 \cdot 26$ & $1 \cdot 37$ \\
\hline
\end{tabular}


the temperature. The individual values obtained in each experiment have been reduced proportionally and plotted about the curve to indicate the order of accuracy.

Table 2 also gives the calculated temperature coefficients, and, for comparison, the temperature coefficients found by Weber (21) for the viscosity of the starch sheath cells of Phaseolus multiflorus.

It will be seen that in both plant protoplasm and in the protoplasm of Nereis eggs the viscosity rises in a similar manner as the temperature falls, though the rise is more rapid in the latter. We are probably justified in assuming that in cases where the viscosity of protoplasm rises with a fall in temperature, the rise is of the order of magnitude shown in the above cases.

\section{Discussion.}

The velocity of a chemical reaction taking place in protoplasm must be affected by changes in the conditions of the protoplasm itself. Since no account has been taken of these changes, the validity of applying Van't Hoff's law to the rate of biological processes has been questioned (1) (16). Even if it be assumed that a chemical reaction does underlie these processes, the conditions of the protoplasm must modify its velocity considerably, because the temperature coefficient of these processes is not almost constant as it is in most chemical processes (Krogh, p. 98 (14).)

Various causes have been suggested to account for this variation of the temperature coefficient of biological processes. Snyder (20) and Rogers (18) have suggested that in even the simplest processes several chemical reactions with different reaction velocities are involved. It seems unnecessary to assume this until full allowance can be made for temperature changes in the conditions of the protoplasm.

It has also been suggested that limiting factors such as the availability of oxygen (14) may affect the velocity of underlying processes. If the temperature coefficient of the oxygen consumption of Mytilus gills is corrected for the diminished solubility of oxygen in sea-water at high temperatures, the temperature coefficient becomes constant between $10^{\circ}$ and $30^{\circ}$. Gray (6) has suggested, tentatively, that this may be of significance. But the rate of oxygen consumption of unstriped muscle (5) does not vary with the oxygen tension, although the effect of temperature on the rate of oxygen consumption appears to be similar to its effect in the case of Mytilus gills.

It is therefore of great importance to determine how variations in the conditions of the protoplasm will affect the velocity of processes occurring in it. Weber (21) points out that changes in viscosity are directly determined by these changes of conditions in the protoplasm. Moreover, NEW SERIES. - VOL. XIII. NO. 2. NOVEMBER, 1924. 
Snyder (20) has drawn attention to the suggestion of Van't Hoff that the temperature coefficients of even simple chemical reactions should be corrected for changes in the viscosity of the medium.

The temperature coefficient of a simple chemical reaction is not quite constant : it falls as the temperature rises, but to a smaller extent than in the case of most biological processes. Snyder shows that if the temperature coefficient of a simple chemical reaction (e.g. $\mathrm{H}_{2} \mathrm{O}_{2}+2 \mathrm{H1}=$ $2 \mathrm{H}_{2} \mathrm{O}+\mathrm{I}_{2}$ ) is corrected for changes in the viscosity of the medium (water), the corrected temperature coefficient becomes almost constant. It seems probable therefore that the temperature coefficients of biological processes should be corrected for changes in the viscosity of the protoplasm, or of that part of the protoplasm in which the processes occur: and that by correcting for changes in viscosity we are approximately correcting for changes in the conditions of the protoplasm.

It is possible that certain structural changes might occur in the protoplasm for which no allowance was made by correcting for viscosity, although they might affect processes taking place in the protoplasm. But a particular case may be noted here. In certain cases biological activities are probably unaffected by changes in the viscosity of the protoplasm. Such a ease is the development of tension by striped muscle during isometric contraction. In this case the tension developed seems to depend on the amount of the antecedent chemical reaction (production of lactic acid) rather than on its velocity, which alone would be affected by the viscosity. Nevertheless if structural changes capable of affecting biological processes occurred in the protoplasm we might expect them to affect the degree of tension developed in this case.

Now, the tension developed by muscle appears to be a surface effect (2). The tension developed at different temperatures during isometric contraction seems to show that the effect of temperature on the underlying physical process is unaltered : the temperature coefficient is small and negative (4). But if a change of temperature produced structural changes great enough to affect biological processes, they would probably be great enough to affect the temperature coefficient in the case considered : they do not appear to do so. There is some probability, therefore, that viscosity is the chief modifying factor in biological processes.

To correct the temperature coefficients of various processes for changes in viscosity with temperature demands knowledge of these changes for the particular protoplasm in each case. These are not known; but if the relative changes are of the order of those occurring in Nereis eggs we should find that the temperature coefficients of various processes would tend to become constant if corrected by viscosity values obtained from these eggs. There will, however, be greatest divergence near $0^{\circ} \mathrm{C}$. The viscosity rises rapidly in this region, and if in other kinds of protoplasm, 
this rise occurred a little earlier or later than it does in Nereis eggs, the correction would be imperfect. Table 3 gives the temperature coefficients of ciliary, heart and amœboid activities corrected by factors derived from the viscosity changes in Nereis eggs. It will be seen that the greatest divergence occurs near $0^{\circ} \mathrm{C}$. The enormous rise in the temperature coefficient near $0^{\circ} \mathrm{C}$. of, for instance, the rate of beat of the Terrapin heart, may indicate that the viscosity of the protoplasm rises far more rapidly in this case than it does in Nereis eggs.

\section{TABLE 3.}

Temperature Coefficients corrected for Changes in Viscosity.

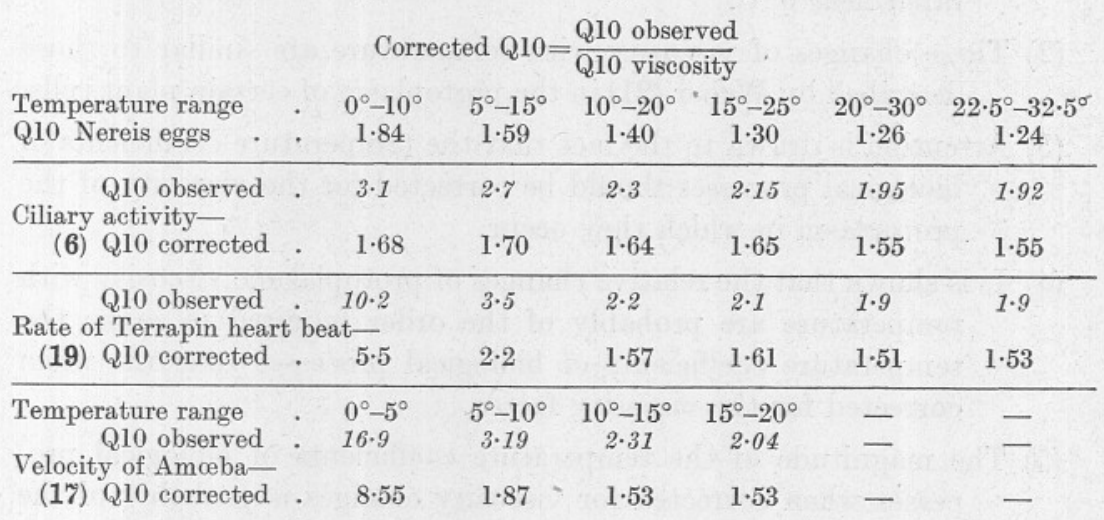

In view of the previous considerations, the corrected temperature coefficients are as constant as could be expected. The values of the corrected temperature coefficients are of the order of the corrected values for chemical reactions. For the reaction $\mathrm{H}_{2} \mathrm{O}_{2}+2 \mathrm{Hl}=\mathrm{I}_{2}+2 \mathrm{H}_{2} \mathrm{O}$ with an observed temperature coefficient about 2 , the corrected temperature coefficient is $1.56(\mathbf{2 0})$.

It has been mentioned that Heilbrunn (11) found that the viscosity of sea-urchin eggs does not rise, but falls, as $0^{\circ} \mathrm{C}$. is approached. Perhaps it is significant that Loeb (15) found the temperature coefficient of the rate of oxidation in sea-urchin (Arbacia) eggs to be approximately constant, instead of rising as the temperature falls, as in most biological processes.

It may be pointed out finally that the rate of most biological processes gradually reaches zero near $0^{\circ} \mathrm{C}$. This is in keeping with the assumption that the viscosity of a watery solution such as protoplasm is important in modifying the rate of these processes.

We may conclude that variations of viscosity of protoplasm with temperature are probably of the order of magnitude required to make 
the corrected temperature coefficients of biological processes constant; and that the value of the corrected temperature coefficients would probably be of the order of the corrected temperature coefficients of chemical reactions.

\section{SUMMARY.}

(1) The effect of temperature on the viscosity of the protoplasm has been determined in the unripe eggs of Nereis diversicolor by the centrifuge method.

The viscosity rises as the temperature falls, the rise becoming rapid near $0^{\circ} \mathrm{C}$.

(2) These changes of viscosity with temperature are similar to those described by Weber (21) in the protoplasm of certain plant cells.

(3) Attention is drawn to the fact that the temperature coefficients of biological processes should be corrected for the viscosity of the protoplasm in which they occur.

(4) It is shown that the relative changes of protoplasmic viscosity with temperature are probably of the order required to make the temperature coefficients of biological processes constant when corrected for the viscosity factor.

(5) The magnitude of the temperature coefficients of biological processes when corrected for viscosity changes is probably of the same order as that of the temperature coefficients of a chemical process when corrected for changes in the viscosity of its medium.

\section{REFERENCES.}

(1) Adrian, E. D. 1914. The Temperature Coefficient of the Refractory Period in Nerve. Journ. Physiol., 48, p. 453.

(2) Bayliss, W. M. 1920. Principles of General Physiology. 3rd edition. Longmans and Co., London.

(3) Chick, H., and Lubrzynska, E. 1914. The Viscosity of some Protein Solutions. Biochem. Journ., 8, p. 59.

(4) Dor, Y. 1920-21. Studies on Muscular Contraction. I. Journ. Physiol., 54, p. 218.

(5) Evans, C. L. 1923. Studies on the Physiology of Plain Muscle. II. Journ. Physiol., 58, p. 22.

(6) Gray, J. 1923. The Mechanism of Ciliary Movement. III. Proc. Roya] Soc., B., 95, p. 6. 
(7) Greely, A. W. 1901. On the analogy between the effects of loss of water and lowering of temperature. Amer. Journ. Physiol., 6, p. 122.

(8) Greely, A. W. 1903. Further studies on the effect of variations in the temperature on animal tissues. Biol. Bull., 5, p. 42.

(9) Greely, A. W. 1904. Experiments on the physical structure of the protoplasm of Paramœcium, etc. Biol. Bull., $\boldsymbol{\eta}$, p. 3.

(10) Hembronn, A. 1922. Eine Neue Methode zur Bestimmung der Viskosität lebender Protoplasten. Jahrb. Wiss. Bot., 61, p. 284.

(11) HeIlbrunn, L. V. 1920. The physical effect of Anæsthetics upon living Protoplasm. Biol. Bull., 39, p. 307.

(12) Heilbrunn, L. V. 1921. Protoplasmic viscosity changes during Mitosis. Journ. Exp. Zool., 34, p. 417.

(13) Henbrunn, L. V. 1924. The Colloid Chemistry of Protoplasm. III. Am. Jl. Physiol., 68, No. 3, p. 645.

(14) Krogh, A. 1916. The respiratory exchange in animals and man. Monographs on Biochemistry. Longmans, Green and Co., London.

(15) Loeв, J. 1913. Artificial Parthenogenesis and Fertilisation. University of Chicago Press, Chicago, Illinois.

(16) LuCAs, K. 1908. The temperature coefficient of the rate of conduction in nerve. Journ. Physiol., 3\%, p. 112.

(17) Pantin, C. F. A. 1924. On the Physiology of Amœboid Movement. II. Brit. Journ. Exp. Biol. I. No. 4, pp. 519-538.

(18) Rogers, C. R. 1911. Studies upon the rate of heart beat in certain living organisms. Amer. Journ. Physiol, 28, p. 81.

(19) Snyder, C. D. 1905. On the influence of temperature upon cardiac contraction, etc. Univ. California Publ., Physiol., 2, No. 15 , p. 125.

(20) SNyder, C. D. 1911. On the meaning of variation in the magnitude of temperature coefficients of physiological processes. Amer. Journ. Physiol., 28, p. 167.

(21) Weber, F. and G. 1916. Die Temperaturabhängigkeit der plasmaviskosität. Ber. Deutsch Botan. Gesell, 34, p. 836.

(22) Weber, F., and Hohenegger, H. 1923. Reversible Viscositätserhöhung des Protoplasmas bei Kälte. Ber. Deutsch. Botan. Gesell., 41, p. 198. 